\title{
Risk factors contributing to truck drivers' non-driving occupational accidents
}

\begin{tabular}{|r|l|}
\hline Journal: & International Journal of Physical Distribution \& Logistics Management \\
\hline Manuscript ID & IJPDLM-06-2017-0216.R2 \\
\hline Manuscript Type: & Research Paper \\
\hline Keywords: & $\begin{array}{l}\text { Critical Incidence Technique, Interview, Occupational accident, } \\
\text { Stakeholder, Safety management, Truck driver, Work outside the cab, Risk } \\
\text { management }\end{array}$ \\
\hline \multicolumn{2}{|l}{} \\
\hline
\end{tabular}




\title{
Risk factors contributing to truck drivers' non-driving occupational accidents
}

\begin{abstract}
Purpose: To identify various individual factors and combinations thereof that can contribute to truck drivers' occupational accidents, particularly connected to work performed outside the $\mathrm{cab}$ in various work environments.

Design/methodology/approach: Seventy-four accidents were analysed through in-depth interviews with truck drivers. These interviews were conducted employing the critical incident technique, and analysed utilising a qualitative content analysis approach.

Findings: The contributing factors identified were categorised into 14 categories. Thirteen of these were grouped into four sections reflecting the drivers' work outside the cab: 'Goods and equipment', 'Loading/unloading area', 'Loading/unloading tasks', and 'Organisation'. A single risk factor was associated with 40 accidents while the other 34 involved combinations of factors.
\end{abstract}

Research limitations/implications: Although the tasks performed by truck drivers in different countries are probably similar, one limitation might be that all the accidents characterised occurred in one country: Sweden.

Practical implications: Our findings reveal that complex combinations of risk factors often contribute to accidents. In addition to the transportation company itself, other stakeholders, such as clients, and designers and manufacturers of technology, may influence the occupational safety of truck drivers. Different stakeholders who could contribute to managerial decision making that is designed to prevent accidents are identified and discussed. Originality/value: This investigation contributes to an in-depth understanding of the causes of accidents in the transportation industry. The findings are discussed from the perspective of the stakeholders and safety management in an attempt to identify key stakeholders who can improve accident prevention. 
Keywords: Critical incident technique, Interview, Occupational accident, Risk management, Safety management, Stakeholder, Truck driver, Work outside the cab

Paper type: Research paper

\section{Introduction}

In addition to the actual driving, truck drivers inspect and maintain their equipment, refuel and load, unload and secure the cargo. Often, they are also responsible for the associated paperwork. To accomplish their tasks, they enter and exit from the cab or trailer repeatedly during a workday (Apostolopoulos et al., 2014; Olson et al., 2009; Smith and Williams, 2014). Thus, truck drivers carry out both static driving and manual work (Wioland, 2013). High prevalence of work-related musculoskeletal disorders, and high accident rates are associated with the trucking industry globally. Furthermore, the constant need for a skilled workforce is emphasised (Apostolopoulos et al., 2010; Douglas and Schwartz, 2016; Shibuya et al., 2010; Smith and Williams, 2014; van der Beek, 2012). Driving, road safety, and vehicle accidents have been discussed in various studies, such as the ones by Corsi et al. (2014) and Mitra (2016). However, in the present study, we focus on a seldom-studied part of truck drivers' work that is related to their tasks outside the cab. Several studies (see Chandler et al., 2017; Friswell and Williamson, 2010; Reiman et al., 2015; Shibuya et al., 2010; Wioland, 2013) have shown that the vast majority of these occupational accidents (referred to below simply as accidents) occur while performing tasks outside the cab.

Occupational accidents involving truck drivers are reported extensively in the literature on occupational health and safety, and approaches to eliminating or reducing the risk for such accidents have been proposed (see, for instance, Davies et al., 2003; Perttula and Salminen, 2012). Nonetheless, a common goal toward accident reduction appears to be missing (Cantor, 2008; Perttula, 2010). Anderson et al. (2017) and Murphy et al. (2018) emphasise the need for new in-depth studies to understand different contextual factors affecting truck drivers' safety. Douglas and Schwarz (2016) urge that a focus should be place on the driver as the unit of analysis. To help achieve such goals, the present study was designed to identify and categorise factors that contribute to accidents by truck drivers, including the relationships between these factors, and to identify key stakeholders who may influence risk prevention. Our approach involved in-depth interviews of truck drivers who have had an accident while working outside the cab; traffic accidents were not included. 


\section{Background}

Transportation work contains special characteristics. During each workday and work shift, a truck driver encounters different variables, such as the routes, weather, traffic conditions and different delivery locations, thus making each workday and shift different (Douglas and Schwartz, 2017). The mode of the transportation also poses varying challenges. For instance, the tasks involved in local and short hauls $(\mathrm{L} / \mathrm{SH})$ differ from those when driving long distances. In addition, practices at the home terminal may differ; for example, the driver may participate in loading, or this may be done by terminal workers. Rough estimations by, for example, Hanowski et al. (2000) and Salmoni et al. (2008), indicate that in L/SH operations only about one-third of the work associated with such operations involves actual driving, the remainder being performed outside of the truck cab.

The driver's work environment outside of the cab includes home terminals or distribution centres, the premises and yards of customers and public streets. Furthermore, in addition to the cab, other aspects of the truck, such as cargo spaces, trailers and tailgate loaders, can be considered part of the truck driver's working environment (Olson et al., 2009; Reiman and Putkonen, 2012; Shibuya et al., 2010). Usually, when not at home terminals and distribution centres, drivers perform their work alone, without being fully monitored by their employer (European Agency for Safety and Health at Work, 2011). While working alone, the driver may face opportunities for unethical and unsafe actions to ease his or her workload, and quicken his or her work. This poses challenges to safety management processes.

Work outside the cab often involves, and is performed, by utilising technical equipment, such as roll cages, dollies, hand trucks, lifting hooks, pallet trucks and racks. These are designed to quicken and ease the workload (Bedinger et al., 2016; Keyserling et al., 1999; McClay, 2008; Reiman et al., 2014). However, such equipment may not always be used, may be used incorrectly or may be suboptimal with respect to ergonomics and usability (Fathallah et al., 2000; McClay, 2008; Torma-Krajewski, 2007). Opportunities to unsafe actions often relate to situations in which the driver chooses to use or not use the equipment available. In such cases, the driver may justify his or her decisions based on the need to keep up with the schedule (Anderson et al., 2017).

In addition to physical accident risks, truck drivers' work is associated with various forms of psychosocial discomfort factors (Schulz et al., 2014; Wioland, 2013). These are factors in the 
social environment that induce psychological reactions. For L/SH transportations, a lack of respect and support from other road users and other stakeholders can be associated with psychosocial stressors. In addition, more generally in the trucking industry, loneliness and health-related issues are also identified causing psychosocial stress (Williams et al., 2017). Truck drivers frequently work with a tight time schedule that they must be able to readjust, if necessary, while still adhering to safety regulations. Furthermore, they may have to deal with clients and other stakeholders such as citizens, which requires skilful communication and cooperation (Wioland, 2013).

Along with these physical and psychosocial risks and challenges, local threats may be present. For instance, in the Nordic countries, changing weather conditions, especially during winter, may induce changes at the ground level (e.g. suddenly from snowy to icy and slippery grounds), lower the usability of equipment, and thus increase the risk for accidents. In addition, continuous movement back and forth from the warm truck cab to the cold outdoors may cause physical and psychosocial stress (Reiman and Putkonen, 2012; van der Beek, 2012).

\section{Stakeholders contributing to safety management}

The driver shortage and high turnover rates have been identified as future challenges to logistics operations (Williams et al., 2017; Douglas and Schwartz, 2016). Safety is an essential element that can contribute to longer working careers and branch reputation (Douglas and Schwartz, 2016). In addition to the human suffering of the driver and his or her relatives, accidents cost money (Manuele, 2011). As underscored, for instance, by an estimation from the Finnish trucking industry by Perttula (2010), occupational accidents may account for nearly $1 \%$ of all supply chain costs.

Even though the drivers can be considered the single most important element to safe and efficient operations (Douglas and Schwartz, 2016; Williams et al., 2017), several stakeholders other than the truck driver can contribute - directly or indirectly — to the driver's safety and work performance. From the perspective of sustainable value chains, various stakeholders, from society to individual employees, can help improve personnel-related matters, including working conditions (Busse et al., 2017; Markley and Davis, 2007; Zink and Fischer, 2013). In the case of truck drivers, contributing stakeholders include, for instance, the different actors at terminals (such as the management personnel of transportation companies, foremen, terminal 
workers, and route/load planners); truck, truck body, and equipment designers and manufacturers, client organisations and their employees; and citizens at the clients' premises, enclosures and buildings, and public and other places that belong to external owners (Cantor, 2008; Reiman and Putkonen, 2012; Shibuya et al., 2010).

Williams et al. (2017) emphasise that there seems to be a lack of respect between different stakeholders, whereas Murphy et al. (2018) discuss whether there are adequate communication possibilities and channels between the drivers and other stakeholders. To concretise these deficiencies, Murphy et al. (2018) highlight in their study that communication problems were identified, especially between the load planners and the drivers. Furthermore, Murphy et al. (2018) highlight the inadequate skills of the managers in discussing and assisting truck drivers with the stressors they may encounter while working.

\section{Material and Methods}

Because our focus was to obtain a nuanced and detailed in-depth understanding of the participants' experiences of accidents in an attempt to identify contributing factors, a qualitative and inductive approach was considered appropriate. This study was pre-approved by the regional ethical review board at Karolinska Institute, Stockholm.

\section{Material}

A registry of occupational accidents that truck drivers had received economic compensation for was used to identify potential participants, and invite them to be interviewed. The registry was obtained from AFA Insurance, a Swedish agency that is jointly owned by the employer and employee organisations. It insures against work-related injuries. Ninety percent of the employees in Sweden are covered by this insurance. The registry included reports on compensated accidents during the 10 past years (2005-2014). Our focus was on drivers whose job description was similar to that of $\mathrm{L} / \mathrm{SH}$ drivers, that is, making multiple delivery stops, and performing tasks outside the cab.

The accidents were categorised by AFA into 11 different types of physical activities that had preceded the accidents. These were (in the order of highest to lowest proportion of the total number of accidents): stumbling; manual materials handling; using lifting equipment; handling the door/port; falling from a height; using pallet truck; getting struck by something falling; traffic; getting crushed by an object; exiting/boarding the vehicle, and using a forklift. 
Because our interest was on tasks performed outside the cab, traffic-related accidents $(\sim 5 \%$ of the AFA material) were excluded. To obtain a selection including all the types of accidents above, 380 drivers were selected in proportion to the size of these physical activity groups, and were invited by letter to be interviewed. For ethical reasons, this letter was sent by the insurance organisation.

The letter of invitation included a description of the study, a form indicating consent of participation, and a pre-paid return envelope. Those who agreed to participate provided a phone number where they could be reached for the interview.

Of the 68 drivers interviewed, four were excluded (two traffic accidents and two non-workrelated accidents). Because eight of the remaining 64 drivers had experienced two accidents, and one had experienced three, a total of 74 accidents were covered. Most of these had occurred 1-5 years (overall median 2$)$ prior to the interviews, with only four exceptions $(6,8$, 10 , and 23 years earlier). At the time of the accident, the respondents had been working as truck drivers for 1-44 years (median 13 years), and seven were female drivers. Most of the accidents had taken place at cargo terminals or customer's loading areas. The geographical locations of the accident sites varied, covering the entire country, and including both urban and rural areas.

\section{Data collection}

Data were collected employing the critical incident technique (CIT) (Flanagan, 1954; Fitzgerald et al., 2008). The aim of the study was to examine all possible aspects of the accident in question, yet we wanted to be able to clearly define the accident against other events, so the CIT was considered suitable. According to the CIT, each interview focused on one critical incident (CI), that is, one specific accident. With the nine interviewees who described more than one accident, the interviews focused on one specific accident at a time. The interviews did not consider incidents other than the CI, nor involve any general discussion of workplace accidents.

Semi-structured telephone interviews were conducted by three of the authors (ALN, MP and IM), and the specific focus of the CIT was supported by an interview guide to ensure that all possible aspects of the accident in question were examined. As the interview guide approach stipulates, the guide gave an overview of the broad topics to be covered, if relevant. The topics of the interview guide were as follows: goods (was there any handling of goods at the time of the incident, etc.), truck and equipment (was the interviewee in or near the truck at the 
time of the incident, was there any handling of equipment, etc.), physical environment, inclement weather, and time of day (how was the physical environment at the place of the incident, etc.), social (were there other persons nearby at the time of the incident, etc.), organisational (how was the interviewee's work schedule at the time of the incident, etc.), and self (was the interviewee new at work at the time of the incident, etc.). In line with the semistructured approach, the interviewer asked clarifying questions or encouraged the interviewee to continue only when necessary. Thus, if an interviewee had not spontaneously covered a topic, the interviewer asked, for example, 'How was the weather that day?', 'Were you alone at that time or were there any other people around?' or 'Tell me more about the equipment you had at hand'. The interviews started with questions concerning background information (how long the interviewee had been working as a driver, and when the accident occurred). The interviewee was then asked to describe what happened when he or she was injured, and when appropriate, clarifying questions were asked. The interviewee's report was condensed and documented in writing by the interviewer during the interview. The interviews continued for approximately $20-40$ minutes.

\section{Data analysis}

A qualitative content analysis was performed by two of the authors (ALN and MP). The specific analytical approach followed the premises of a directed content analysis, as described by Hsieh and Shannon (2005). No pre-determined codes were used in the present study, which is common in directed content analysis. However, the analysis was directed by the narrow focus of the research question, aiming solely at identifying factors contributing to accidents. So, the analysis did therefore resonate with this method.

Only manifest material was subject to analysis, that is, there was no interpretation of issues not expressed verbally by the interviewees. The first step in the analysis was to read and reread the interview notes to get a grip of the data set as a whole. In the analysis process, ALN and MP initially worked independently, extracting data relevant for the research question from the interviews, and coding these data using preliminary codes, which were then discussed to reach consensus on a final set of codes (see Table 1). Subsequently, ALN and MP independently coded the entire material, collating data relevant to each code and collating codes into preliminary categories. Next, inconsistencies between the two preliminary sets of categories were discussed with a third author (IM), and these categories were critically and independently re-examined. Thus, discussions and independent analyses were alternated in an 
iterative process until a final set of categories could be established. The interpretive validity (i.e. that interpretations are not based on the researcher's perspective but that of the participant) of the findings was assured through the independent participation of three researchers in this analytical process.

\section{TABLE 1 ABOUT HERE}

\section{Results}

\section{Factors contributing to critical incidents (CIs)}

The analysis of the factors contributing to the accidents resulted in 14 categories. In each individual accident, several different factors were often involved, and one accident could thus provide information relevant to several categories. Thirteen of the 14 categories were grouped into four sections that reflected the drivers' work outside the cab: 'Goods and equipment', 'Loading/unloading area', 'Loading/unloading tasks', and 'Organisation' (see Figure 1). In addition, one category related to the driver's temporary inattention/distraction for no identifiable reason was identified.

\section{FIGURE 1 HERE}

The categories 'Goods and equipment' and 'Loading/unloading area' covered risks related to the physical work environment. In such categories, the accident risk was related to technical or structural deficiencies at the work environment or concerning the load. In practice, such deficiencies may be seen e.g. as equipment failures or different obstacles at the delivery routes.

The 'Loading/unloading tasks' and 'Organisation' categories involved accident risks related to structural conditions, organisational support and the driver's own behaviour and choices that he or she made during work. In practice, they were often related to the guidance and support by the employer, and the ways work is actually performed. Furthermore, in the 'Goods and equipment', 'Loading/unloading area' and 'Loading/unloading tasks' sections, physical risks for accidents could be identified, whereas 'Organisation' involved psychosocial risk factors that could primarily be associated with stress. In the results section below, examples from the interview notes are presented (in italics) to illustrate the categories. 


\section{Goods and equipment}

The section 'Goods and equipment' included three categories related to the goods delivered and the equipment used in delivering the goods: 'Unsuitable packaging', 'Excess stowage', and 'Unsafe placement of goods'.

Unsuitable packaging: Goods with unsuitable or inadequate packaging in many cases were also both bulky and fragile, for example, window glass panes. As a consequence, the existing tools at hand (such as a hand truck or forklift) couldn't be used at all situations. In all descriptions of unsuitable packaging, the load became unstable and collapsed, causing an accident. In one example, the interviewee was unloading a large glass window (a front window for a truck), which the supplier had packed in a wooden frame on a very narrow, home-made pallet, i.e. with a different format from a standard pallet. /.../ The goods collapsed and fell over the interviewee's hand.

Excess stowage: In certain cases, safe handling was prevented by the shape or size of the cargo. For instance, the driver could not load a good that was too large or of an odd shape with the existing equipment. A typical consequence was that the driver had to climb up on the load to make sure that all the goods could be loaded, and then slipped or otherwise fell, sustaining an injury. One interviewee had loaded drainage tanks and pipes. Customers book the load per volume, and the goods do not always fit well into the cargo space. In order to bring along all the goods, the interviewee climbed up on the loaded tanks, and put up pipes. The interviewee slipped on the rounded edge of the tank and fell about 3.5 meters.

Unsafe placement of goods in the cargo space: In certain accidents, goods had been loaded or placed incorrectly, which in some cases led to the driver being hit by falling items during loading and unloading. Typically, the truck had been loaded by someone other than the driver, who for various reasons, often related to lack of time, had not checked the loading.

In addition to goods, this section included three categories related to equipment, defined broadly as tools utilised to aid in transferring goods (for instance, cargo pallets, trucks and cranes), as well as portions of the truck's body and cargo space.

Lack of proper equipment: This category applied primarily to the tools for loading/unloading, which were either unsuitable for handling the goods in question or missing entirely. In more than one case, the goods required a truck with long forks, but only short forks were provided. 
When equipment was missing or entirely unsuitable, the loading/unloading had to be performed manually. Many of these accidents involved handling of goods at the customers' premises. In one case, special heavy pallets (several hundred kilograms) with boat engines were to be unloaded at a customer's storage place. The customer did not have a truck with forks long enough to reach under the pallets. The interviewee helped by pulling the pallets forward by hand; as these special pallets cannot be pulled with a regular pallet jack. A packing tape that the interviewee was holding while pulling came off. The interviewee fell out of the truck and down to the ground. One elbow was crushed.

Unsafe construction of equipment: In some cases, the equipment lacked safety devices, such as protection against falls from the trailer. In other cases, the design itself involved a risk, for example, when the driver was forced to climb onto the vehicle to check the cargo. With several accidents, the tools were not designed for the task at hand, for example, for carrying the particular goods in question or for use on the loading surface. In the latter situations, the hand truck, roller cage or the like was not designed for handling the cargo outdoors on gravel or snow, so the carrier device and goods fell. In other cases, the driver chose not to use the unsafe equipment and carried out the loading/unloading manually.

Defective equipment: Broken or worn-out equipment included parts in and on the vehicle, as well as for loading and unloading, resulting in several accidents, mainly due to defective anchoring of goods or girders in the cargo space. Cutting and crushing because of broken or stuck equipment were also recurrent phenomena. One interviewee was unloading goods. As he lifted up the bar, which was holding the door closed by being fixed in a rail on the wall, the bar came off and hit him in the head. It hurt, but the interviewee carried on working. When he later looked in a mirror he saw that blood seeped from his mouth.

\section{Loading/unloading area}

The section 'Loading/unloading area' referred in general to the physical space where cargo was handled (the outdoor loading area, terminal, loading dock, tail lift, and cargo space), and encompassed two categories.

Crowding/disorder in the loading area: In these examples, the safe use of suitable equipment for loading and unloading was hampered by the presence of large amounts of goods, which created disorder, and reduced accessibility to the terminal or loading dock, forcing the driver to pick unsafe choices when performing the task. One interviewee was loading the trailer. He 
was standing on the truck, and to rearrange the load, he pulled goods out of the trailer. He collided with a forklift truck. It was crowded and the forklift driver did not see the interviewee moving backwards. The accident happened early in the morning on a normal stressful-asusual working day, according to interviewee. There are 10 positions at the loading platform, where 15 trucks with trailers load, starting at 5 o'clock and are on the road on their way to the customers no later than 7.

Unsafe surface: Here, lack of service or safe adjustment to the ground or floor of the loading area typically led to tripping, stumbling or slipping. Many of these situations involved insufficient snow removal and insufficient sanding of icy surfaces while other accidents resulted from uneven ground or stairs.

\section{Loading and unloading tasks}

Four categories were related to unsafe procedures for the handling of goods (loading and unloading).

Unloading heavy loads alone: In some cases, the driver unloaded bulky or very heavy goods alone, particularly on a customer's premises, even though help from another person was required. Some of these accidents also involved deficiencies in the packaging or equipment that the driver tried to compensate for by parrying the item with his or her own body, which would not have been necessary if he or she had had assistance in unloading. The interviewee in the example in the category Unsuitable packaging above was unloading a large glass window alone. The customer had an agreement for goods to be delivered "without a signature", i.e. no one receives the delivery and there is no one that can help with the unloading.

Voluntary participation in unloading: In certain accidents, the driver helped with unloading, even though this was not his or her task. Often, this was because the volume or packaging mode of the goods was particularly difficult to handle. For example, one driver climbed up on the load to manually assist the driver of the forklift because otherwise some of the goods would not have been unloaded. Both interviewees in the examples in the categories Excess stowage and Lack of proper equipment above, participated voluntarily in loading/unloading tasks. As one IV said: "You want to be helpful, but you also want to move on as soon as possible" 
Manual lifting: In some cases, manual lifting of goods, often heavy, was required, for example, because of special packaging that could not be handled by standard equipment for unloading. Other accidents involved stress: the driver felt that the schedule did not allow enough time to search for and retrieve the proper equipment.

Unsafe handling of goods: A typical example of this was when the standard route for climbing on to the vehicle while handling the goods was blocked, so the driver chose to climb up onto the cargo instead, and then fell. Sometimes, the cargo was of a type or volume that could not be safely handled on the truck in question. One interviewee delivered white goods (stoves, washing machines, etc.). The truck had been loaded by terminal workers; the interviewee unloaded alone. Double-loading were commonly applied, i.e. two items were placed on top of each other. A washing machine was unstably standing on top of another; it fell during unloading, and hit, together with the hand truck the interviewee's foot.

\section{Organisation}

The section on organisation was more complex than the others, and included the category of 'Imbalance between demands and resources', which involved risk related to psychosocial stress.

Imbalance between demands and resources: Accidents due to work-related stress, often in combination with one or more of the other factors described above, were common. Thus, in some of these cases, the driver utilised defective or unsuitable equipment or performed manual lifting because he or she felt there was too little time for a more suitable procedure. In other cases, the driver felt compelled to participate in or perform the loading or unloading alone because he or she felt responsible for completing the job, even though loading or unloading was not his or her task, and he or she did not have access to the proper equipment or routines. A number of interviewees also reported that their supervisors exhibited an explicitly negative attitude toward following safety procedures and maintaining safety margins, if this would require extra time, for example, monitoring loading performed by someone else. In the case of one interviewee, the goods had not been properly secured during loading, which had been done by another person. The interviewee had not checked the load before departure, due to stress because of a tight time schedule. The interviewee explained that the supervisor urges drivers not to take time to check the load; supervisor would 
complain and there would be a conflict between the supervisor and the driver, if the driver should start to adjust the loading.

In some of the situations, the stress was described as specifically related to the day in question, for example, when an additional delivery(-ies) was added to a pre-planned schedule. In other cases, the stress was described as persistent, for example, when drivers were forced to hurry with the loading every morning to avoid rush hour traffic or if the delivery schedule was so tight that there was no time for anything extra. In addition, situations involving fatigue due to prolonged overtime were assigned to this category.

\section{Inattention/distraction}

Even without work-related stress, the drivers sometimes acted in a manner that contributed to the accident, most often by being inattentive during a routine task, resulting in, for example, pinching when closing a door or falling when stepping off the cargo bed. In some cases, interviewees mentioned 'private' stress that was still occasionally related to the work, for example, being delayed by work when one is supposed to pick up children from the day care centre, or being eager to go home after working and sleeping in the truck for several days.

\section{Contributing factors and their combinations}

A single contributing factor (i.e., category) could be identified for a total of 40 accidents. More than one-third (37.5\%) of these were related to problems with the equipment in use (defective or unsafe construction or total lack). 'Unsafe surface' was the major contributing factor in seven cases (17.5\%), and 'Inattention/distraction' and 'Imbalance between demands and resources' contributed to $12.5 \%$ and $10 \%$, respectively.

Two or more factors contributed to the remaining 34 accidents. The most common were 'Unsafe surface' in combination with 'Imbalance between demands and resources' (four cases) and 'Unsafe construction of equipment' in combination with 'Inattention/distraction' (three cases), accounting together for roughly $20 \%$ of the cases. Half of the other 23 combinations included 'Imbalance between demands and resources', and a factor related to equipment was part of $54 \%$ of the combinations. Furthermore, five to seven different combinations included 'Lack of proper equipment', 'Unsafe handling of goods', 'Unsafe construction of equipment' and 'Un-/loading manually'. The different combinations are presented in Table 2. 


\section{TABLE 2 ABOUT HERE}

\section{Discussion}

Previous investigations have consistently shown that the vast majority of occupational accidents involving truck drivers occur outside the cab, which is why we chose to focused on such work and did not consider traffic accidents. Swedish truck drivers who had been involved in an accident were interviewed; here, we utilised the critical incident technique to identify contributory factors. We found that various factors, either alone or in a combination, can contribute to these accidents. Our findings parallel the holistic work system categorisation of truck drivers by Murphy et al. (2018), underscoring the need to pay attention to factors in several domains. According to Murphy et al. (2018), drivers' work systems are composed of an array of different work tasks that the drivers perform by using (or not using) technical equipment in certain work environments. Drivers' actions are guided and supported by organisational support and practices. As in their study, our study focused on and discussed truck drivers' microergonomic work systems, that is, the focus was on singular drivers as a unit of analysis and discussed the practical work environments in which the tasks were performed. Similarly, as in the work system categorisation, we took a holistic approach, and discussed the organisational and social conditions, in addition to work equipment and environment.

As noted by various authors (e.g., Murphy et al., 2018), truck drivers mainly work alone and in a variety of different environments, the quality of which varies and may involve hazards for physical accidents. However, work environments, or as we categorise in this study-loading and unloading area, either alone or in combination with other factors - contributed to only one-fifth of the cases.

Psychosocial risk factors were also identified. These stress-related factors, referring to the category 'Imbalance between demands and resources', were involved in almost half of the combinations of different risk factors. This is not unexpected because stress induces dysfunctional decision making which adversely affects risk-taking (Starcke and Brand, 2012). The present study was not designed to examine the specific psychological processes associated with the stress-related factor that may have contributed to the accidents. However, typical stress symptoms such as problems in concentrating, irritability, forgetfulness, and the 
ones relating to long-term stress, such as fatigue and accentuated cognitive insufficiency, may well be included in the factor.

Consequently, in the presence of other risk factors or an unexpected situation, stress may amplify the risk for an accident. Moreover, employee safety behaviour strongly relates to the organisational context, that is, policies, practices, safety climate, and leadership (Beus et al., 2016). In the present study, this was distinctly exemplified by drivers' experiences of negative attitudes among supervisors toward following safety procedures when following these rules would take time. This attitude was in turn experienced to increase drivers' stress, in line with what is known about leader stress, the quality of the leadership and their potential to influence employee stress (Harms et al., 2017). Moreover, organisational behaviour also influenced the physical environment. Accordingly, not only stress and risk-taking, but also the occurrence of defective equipment, was indicative of the organisation's policies and procedures and its safety climate.

However, in addition to focusing on singular intra-organisational work systems, we also paid attention to larger organisational macroergonomic work systems, that is, systems and arrangements between different stakeholders and their cooperation processes and actions. Special attention was paid to identifying stakeholders that could contribute to long-lasting and efficient safety management processes.

\section{Key contributors}

Drawing on the findings from the present study and from previous research, we have outlined a conceptual model including the key stakeholders and their potential contributions to risk management regarding drivers' work environment (Table 3). Most reports in this area of research focus on identifying possible risks and hazards at work without examining in detail which key stakeholders could contribute most effectively to risk management. As highlighted by Douglas and Schwartz (2016), truck drivers are influenced by regulatory, organisational and external forces. Regulatory forces may lead the driver to situations where ethical decision making is required. An ethical decision may relate to questions of whether the driver is willing to make minor violations against regulations. Such decisions are constantly made on the road by, for instance, assessing whether schedules could be kept by ignoring speed and driving time limits (Doulas and Schwartz, 2017). Similarly, in work tasks performed outside the cab, the driver constantly makes different decisions, torn between doing the job safely, and keeping up with the schedule. Often, these decisions may be considered minor or are 
made subconsciously. As an example, the driver may choose whether to jump from the cab instead of climbing, or may refuse to use tools for materials handling. In general, organisational practices and culture guide employees in such situations where decisions are made. However, as pointed out by Huang et al. (2013) truck drivers, being alone, seem to have more of an individually led perception of safety instead of shared organisational perceptions. This poses challenges to employers and their safety management processes. In accordance with general safety management principles and organisational practices (e.g., Glendon et al., 2006), management should be committed to safety, and should set clear objectives not only within the organisation, but also communicating with relevant stakeholders. In complex organisational settings (see, e.g., Mattson, 2015), such as the management of a logistics value chain, a systems approach involving recognition of all relevant aspects, and stakeholders and their interconnections is vital for designing long-lasting solutions that promote safety. Such improvements may require time and further negotiation between the transportation company and the client.

Furthermore, as noted by Wioland (2013), modifications to certain work environments may lead to undesirable effects in another working situation, and a balance between all parties must be attained. This is a particular challenge to the management of the logistics value chain, where various different stakeholders can be identified. In fact, the performance of transportation companies regarding occupational safety relies on the safety skills and knowledge of their employees, leaving more room for human errors and consequential accidents that can influence the activities and performance of various stakeholders adversely.

The present investigation reinforces the variety and complexity of factors contributing to occupational accidents by truck drivers (Mitra, 2016; Murphy et al., 2018). As an interpretative reflection, we considered the contributory factors from the stakeholder management perspective. For instance, Wen (2012) urges a deepening of the cooperation between different stakeholders at logistics chains to improve competitive advantage. For this purpose, we have made a conceptual proposal in Table 3 where we have summarised the broad stakeholder complexity by identifying their roles and possible effect on risk-mitigation processes. Here, we categorise the key stakeholders inside a transportation company and inside a logistics value chain as described by Cantor (2008), Shibuya et al. (2010), and Reiman and Putkonen (2012). The value chain is thus simplified to consist of stakeholders who are considered to have a direct effect on truck driver safety. Thus, clients and providers of technology are included in addition to transportation companies (see Table 3). As a future 
research challenge (RC1), we highlight the need for broad stakeholder cooperation in delivery transportation value chains to understand the parallel possibilities between sustainable longlasting risk-reduction processes and competitive advantage through, for instance, a stable workforce, flexibility of operations, lower operating costs, higher customer satisfaction, deeper customer relationships, improved company reputation, and eventually, improved overall productivity.

\section{TABLE 3 ABOUT HERE}

Key stakeholders inside the transportation company include, in addition to the truck drivers themselves, foremen, upper management and other personnel, such as terminal employees and route/load planners, who all contribute to the work environment. As mentioned earlier, although they actually face the risk of accidents, the possibilities for drivers to directly contribute to accident prevention are generally limited to performing their work in a safe manner, following rules and practices agreed upon, and informing appropriate stakeholders about possible hazards related to work tasks, the environment and technologies. Accordingly, the system for reporting anomalies and hazards must be effective. A study by Murphy et al. (2018) shows that there seem to be problems related to managers' skills in discussing more complex psychosocial stressors, whereas managers are used to discussing technical issues. Management is emphasised as a key stakeholder that could contribute to all categories that were identified. Management defines the formal safety management policies, and eventually enables a good safety climate. In practice, the responsibilities of upper management and foremen include providing safe working conditions under all circumstances, for example, by arranging reasonable schedules, designing appropriate prevention measures, ensuring that the appropriate equipment is available, and encouraging employees to report possible hazards. In addition, management is responsible for discussing and agreeing on various issues, including accident prevention, with clients. We highlight as a future research challenge (RC2) paying attention to studying managers' safety perceptions in the context of pressure from tight schedules. We highlight this also as a practical development issue in the transportation branch.

Moreover, discussion processes between different personnel groups should be acknowledged and developed. Route and load planners, and terminal employees are responsible for 
promoting safe transportation as well. Their responsibilities include the planning (and often loading) of the deliveries. The findings by Murphy et al. (2018) emphasise the need for proper organisational communication processes, and point out that there seems to be deficiencies in communication, especially between load planners and drivers. Future research should focus on studying the root causes for these inadequacies (RC3).

Transportation companies often lack the tools and capability to monitor safety in the environments provided by their clients. These clients are actually the stakeholders who, in practice, can best ensure safe work outside the cab when the driver is loading or unloading at their premises, enclosures or buildings (Table 3). In addition, external owners of these client environments, and even those in charge of public places, can be considered key stakeholders. Clients and other stakeholders can help ensure safety (and accessibility, usability and ergonomics) in the environments for which they are responsible, as well as provide the appropriate tools and aids to assist drivers in their work. However, due to the broad range of different external stakeholders, it is often complex to identify the stakeholders that are in a key position to provide solutions to the problems. Our effort in identifying such stakeholders is a step toward gaining more understanding of the variety of different stakeholders in the value chain in the context of safety management. Future studies should focus on identifying what would be the most effective initiatives for different stakeholders to contribute to risk management processes (RQ4).

The providers of technology who can contribute to work safety can be roughly divided into those who design and manufacture equipment, and those who design and manufacture the truck (including the truck's body) itself (Table 3). Both groups can contribute directly to improvements in safety although their contribution is often related to the demands that other stakeholders make. Future research should aim at studying how these demands could be most effectively embedded in design processes. A study by Reiman and Putkonen (2012) shows different practical processes that can produce and share visual risk information to designers. Future research should also focus on participatory user-centred development processes at the delivery transportation branch (RQ5).

\section{Conclusions}

Truck drivers face physical and psychosocial risks that can lead to occupational accidents. The current study focused on risk factors outside the cab in various kinds of work environments, such as home terminals, the premises of clients and public places. Safety 
management in such work environments is challenging because the employer cannot provide continuous supervision. Thus, occupational safety depends on the drivers' skills and abilities to cope with the risks they face.

Seventy-four occupational accidents were examined using the critical incident technique, and 14 categories of contributory risk factors were identified. Risks related to the physical work environment, to structural conditions and to behaviour were identified. This categorisation revealed that somewhat less than half of the accidents involved two or more contributing factors.

The variety and combinations of contributing factors pose challenges for occupational safety management. Several other stakeholder groups that can exert an influence on the occupational safety of these drivers were identified here, including designers and manufacturers of technology. However, currently, the roles and channels of influence are vague, and more indepth discussions among stakeholders are desired.

\section{Acknowledgements}

This study was supported financially by AFA Insurance (grant number 140229).

We are grateful to professor emeritus Tore J Larsson from KTH Royal Institute of Technology for his support in the selection of the drivers who were invited to be interviewed.

\section{References}

Anderson, N., Smith, C.K. and Byrd, J.L. (2017), "Work-related injury factors and safety climate perception in truck drivers", American Journal of Industrial Medicine, Vol. 60 No. 8, pp. 711-723.

Apostolopoulos, Y., Sönmez, S., Shattell, M.M. and Belzer, M. (2010), “Worksite-induced morbidities among truck drivers in the United States”, AAOHN Journal, Vol. 58 No. 7, pp. 285-296.

Apostolopoulos, Y., Lemke, M. and Sönmez, S. (2014), "Risks endemic to long-haul trucking in North America: strategies to protect and promote driver well-being", New Solutions, Vol. 24 No. 1, pp. 57-81. 
Bedinger, M., Walker, G.H., Piecyk, M. and Greening, P. (2016), “21st century trucking: A trajectory for ergonomics and road freight", Applied Ergonomics, Vol. 53 No. Part B, pp. 343-356.

Beus, J.M., McCord, M.A. and Zohar, D. (2016), "Workplace safety. A review and research synthesis”, Organizational Psychology Review, Vol 6 No. 4, pp. 352-381.

Busse, C., Schleper, M.C., Weilenmann, J. and Wagner, S.M. (2017), "Extending the supply chain visibility boundary: Utilizing stakeholders for identifying supply chain sustainability risks", International Journal of Physical Distribution \& Logistics Management, Vol. 47 No. 1, pp. 18-40.

Cantor, D.E. (2008), "Workplace safety in the supply chain: a review of the literature and call for research", International Journal of Logistics Management, Vol. 19 No. 1, pp. 65-83.

Chandler, M.C., Bunn, T.L. and Slavova, S. (2017), "Narrative and quantitative analyses of workers' compensation-covered injuries in short-haul vs. long-haul trucking", International Journal of Injury Control and Safety Promotion, Vol. 24 No. 1, pp. 120-130.

Corsi, T.M., Grimm, C., Cantor, D. and Wright, D. (2014), "Should smaller commercial trucks be subject to safety regulations?”, Transportation Journal, Vol. 53 No. 2, pp. 117142.

Davies, J.C., Kemp, G.J., Frostick, S.P., Dickinson, C.E. and McElwaine, J. (2003), "Manual handling injuries and long term disability", Safety Science, Vol. 41 No. 7, pp. 611-625.

Douglas, M. and Schwartz, S. (2016), "Truck driver safety: An evolutionary research approach", Transportation Journal, Vol. 55 No. 3, pp. 258-281.

Douglas, M. and Schwartz, S. (2017), "Knights of the road: Safety, ethics, and the professional truck driver", Journal of Business Ethics, Vol. 142 No. 3, pp 567-588.

European Agency for Safety and Health at Work (2011), A review of accidents and injuries to road transport drivers, Publications Office of the European Union, Luxembourg.

Fathallah, F.A., Grönqvist, R. and Cotnam, J.P. (2000), "Estimated slip potential on icy surfaces during various methods of exiting commercial tractors, trailers and trucks", Safety Science, Vol. 36 No. 2, pp. 69-81. 
Fitzgerald, K., Seale, N. S., Kerins, C. A., \& McElvaney, R. (2008), "The critical incident technique: A useful tool for conducting qualitative research". Journal of Dental Education, Vol. 72 No. 3, pp. 299-304.

Flanagan, J. C. (1954), “The critical incident technique”, Psychological Bulletin, Vol. 51 No. 4, pp. 327-358.

Friswell, R. and Williamson, A. (2010), "Work characteristics associated with injury among light/short-haul transport drivers", Accident Analysis and Prevention, Vol. 42 No. 6, pp. 2068-2074.

Glendon, A.I., Clarke, S.G. and Mckenna, E.F. (2006), Human Safety and Risk Management, Taylor \& Francis Group, Boca Raton, FL.

Hanowski, R.J., Wierwille, W.W., Garness, S.A., Dingus, T.A., Knipling, R.R. and Carroll, R.J. (2000), “A Field Evaluation of Safety Issues in Local/short Haul Trucking”. In Proceedings of the Human Factors and Ergonomics Society Annual Meeting, pp. 365-368.

Harms, p.D., Credé, M., Tynan, M., Leon, M. and Jeung, W. (2017), “Leadership and stress: A meta-analytic review", The Leadership Quarterly, Vol. 28 No. 1, pp. 178-194.

Hsieh, H. F. and Shannon, S. E. (2005), “Three approaches to qualitative content analysis”, Qualitative Health Research, Vol. 15 No. 9, pp. 1277-1288.

Huang Y-h, Zohar, D., Robertson, M.M., Garabet, A., Lee, J. and Murphy, L.A. (2013), "Development and validation of safety climate scales for lone workers using truck drivers as exemplar", Transport Research Part F: Traffic Psychology and Behaviour, Vol. 17 No. Feb, pp. 5-19.

Keyserling, W.M., Monroe, K.A., Woolley, C.B. and Ulin, S.S. (1999), "Ergonomic Considerations in Trucking Operations: An evaluation of Hand Truck and Ramps", American Industrial Hygiene Association Journal, Vol. 60 No. 1, pp. 22-31.

Manuele, FA. (2011), “Accident Costs. Rethinking ratios of indirect to direct costs”, Professional Safety, Vol. 56 No. 1, pp. 39-47.

Markley, M.J. and Davis, L. (2007), “Exploring future competitive advantage through sustainable supply chains", International Journal of Physical Distribution \& Logistics Management, Vol. 37 No. 9, pp. 763-774. 
Mattson, M. (2015), "Promoting safety in organizations. The role of leadership and managerial practices", Doctoral thesis, Stockholm University, Stockholm, Sweden.

McClay, R.E. (2008), “Truck falls: examining the nature of the problem”, Professional Safety, Vol. 53 No. 5, pp. 26-35.

Mitra, S. (2016), "Analysis of truck accidents using structural equation models", Transportation Journal, Vol. 55 No. 4, pp. 382-399.

Murphy, L.A., Huang, Y-h., Robertson, M.M., Jeffries, S. and Dainoff, M.J. (2018), “A sociotechnical systems approach to enhance safety climate in the trucking industry: Results of an in-depth investigation", Applied Ergonomics, Vol. 66, pp 70-81.

Olson, R., Hahn, D.I. and Buckert, A. (2009), "Predictors of severe trunk postures among short-haul truck drivers during non-driving tasks: an exploratory investigation involving video-assessment and driver behavioural self-monitoring”, Ergonomics, Vol. 52 No. 6, pp. 707-702.

Perttula, P. (2010), "Safety of a logistics chain: A case study", Logistics Research, Vol. 2, No. 3-4, pp.159-163.

Perttula, P. and Salminen, S. (2012), "Workplace Accidents in Materials Transfer in Finland", International Journal of Occupational Safety and Ergonomics, Vol. 18 No. 4, pp. 3-10.

Reiman, A., Pekkala, J., Väyrynen, S., Putkonen, A. and Forsman, M. (2014), "Participatory Video-Assisted Evaluation of Truck Drivers' Work Outside Cab: Deliveries in Two Types of Transport", International Journal of Occupational Safety and Ergonomics, Vol. 20 No. 3, pp. 477-489.

Reiman, A. and Putkonen, A. (2012), "Ergonomics development needs in truck body design From video analyses to solution proposals", International Journal of Human Factors and Ergonomics, Vol. 1 No. 1, pp. 58-73.

Reiman, A., Putkonen, A., Nevala, N., Nyberg, M., Väyrynen, S. and Forsman, M. (2015), “Delivery Truck Drivers' Work Outside Their Cabs - Ergonomic Video Analyses Supplemented with National Accident Statistics", Human Factors and Ergonomics in Manufacturing \& Service Industries, Vol. 25 No. 3, pp. 340-352.

Salmoni, A.W., Cann, A.P., Gillin, E.K. and Eger, T.R. (2008), "Case studies in whole-body vibration assessment in the transportation industry - Challenges in the field", International Journal of Industrial Ergonomics, Vol. 38 No. 9-10, pp. 783-791. 
Schulz, S.A., Luthans, K.W. and Messersmith, J.G. (2014), "Psychological capital: A new tool for driver retention", International Journal of Physical Distribution \& Logistics Management, Vol. 44 No. 8/9, pp. 621-634.

Shibuya, H., Cleal, B. and Kines, P. (2010), "Hazard scenarios of truck drivers' occupational accidents on and around trucks during loading and unloading", Accident Analysis and Prevention, Vol. 42 No. 1, pp. 19-29.

Smith, C.K. and Williams, J. (2014), "Work related injuries in Washington State's Trucking Industry, by industry sector and occupation", Accident Analysis and Prevention, Vol. 65 No. April, pp. 63-71.

Starcke, K., and Brand, M. (2012), “Decision making under stress: a selective review”, Neuroscience \& Biobehavioral Reviews, Vol. 36 No 4, pp. 1228-1248.

Torma-Krajewski, J. (2007), "Ergonomics and design issues with prill trucks”, Mining Technology, Vol. 116 No. 4, pp. 153-157.

van der Beek, A.J. (2012), "World at work: truck drivers", Occupational and Environmental Medicine, Vol. 69 No. 4, pp. 291-295.

Wen, Y-H. (2012), "Impact of collaborative transportation management on logistics capability and competitive advantage for the carrier", Transportation Journal, Vol. 51 No. 4, pp. $452-473$.

Williams, D.F. Jr., Thomas, S.P. and Liao-Troth, S. (2017), “The truck driver experience: identifying psychological stressors from the voice of the driver", Transportation Journal, Vol. 56 No. 1, pp. 54-76.

Wioland, L. (2013), "Ergonomic analyses within the French transport and logistics sector: First steps towards a new "act elsewhere" prevention approach", Accident Analysis and Prevention, Vol. 59 No. October, pp. 213-220.

Zink, K.J. and Fischer, K. (2013), "Do we need sustainability as a new approach in human factors and ergonomics?", Ergonomics, Vol. 56 No. 3, pp. 48-356. 


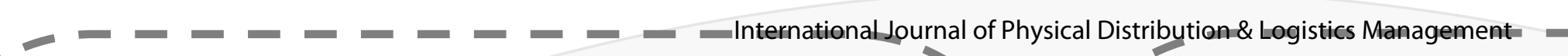

Structural

conditions and

behaviour

Imbalance

\section{behaviour}

/distraction

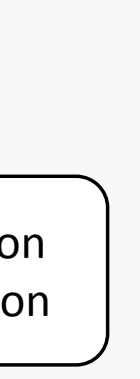

tween resources

and demands
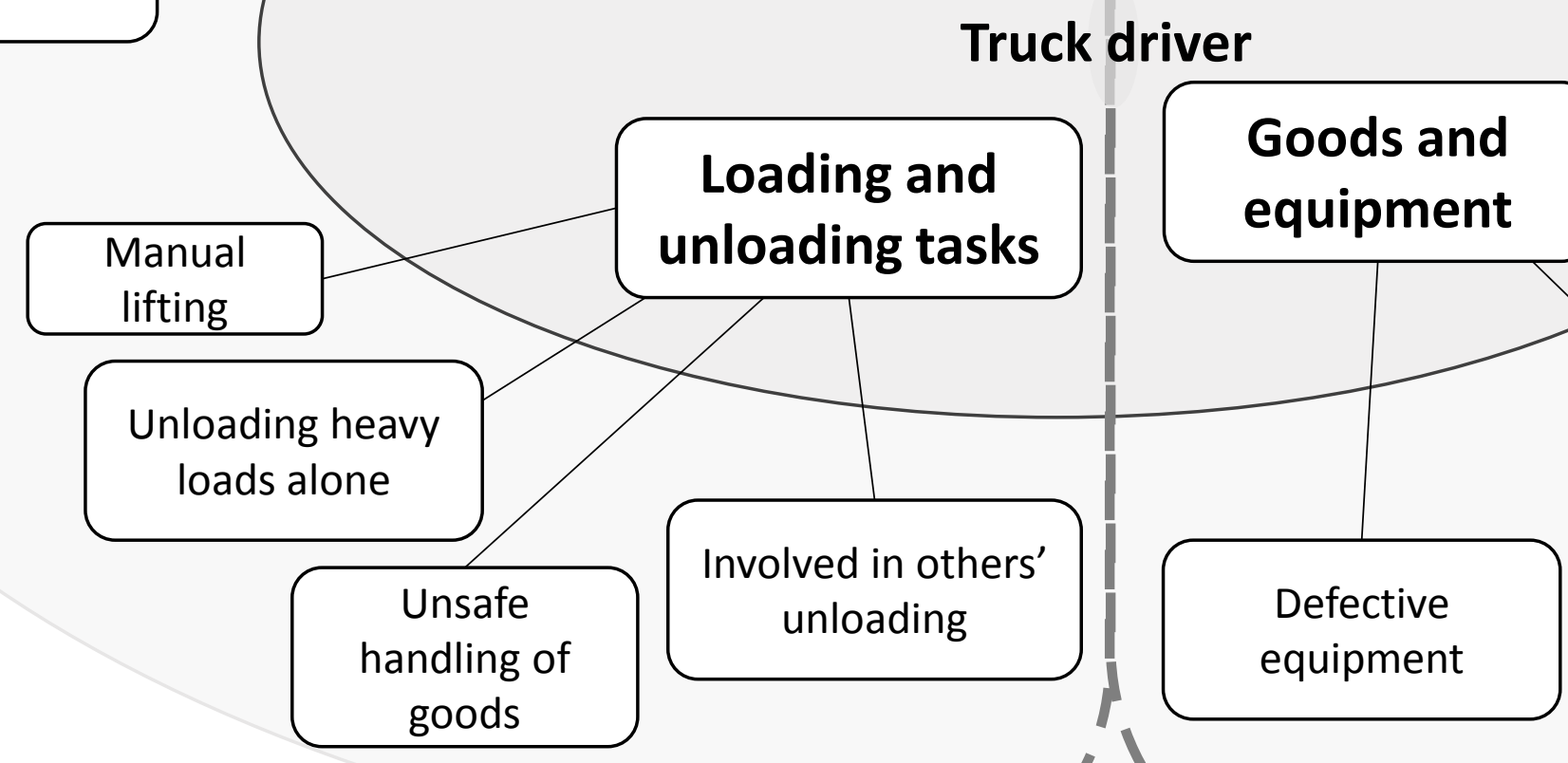

Crowding

/disorder

Physical work

environment

Page 24 of 28 
Fig 1. The categories identified (outer ellipse, light grey) and four thematic sections (inner ellipse, darker grey). 
Table 1. Coding system with some examples.

\begin{tabular}{|c|c|c|}
\hline Data excerpt & Subcategory & Category \\
\hline $\begin{array}{l}\text { the terminal was crowded, the interviewee } \\
\text { did not see the pallet jack standing behind. }\end{array}$ & \multirow{4}{*}{$\begin{array}{l}\text { Crowding/disorder } \\
\text { in the loading area }\end{array}$} & \multirow{8}{*}{$\begin{array}{l}\text { Loading/unloading } \\
\text { area }\end{array}$} \\
\hline $\begin{array}{l}\text { Some goods was on the way at the loading } \\
\text { dock. The goods should have been moved to } \\
\text { be able to pass the pallet jack. }\end{array}$ & & \\
\hline $\begin{array}{l}\text { Interviewee's truck collided with a pallet } \\
\text { jack that stood under a pallet. }\end{array}$ & & \\
\hline $\begin{array}{l}\text { It was crowded and the forklift driver did } \\
\text { not see the interviewee. }\end{array}$ & & \\
\hline $\begin{array}{l}\text { Heavy snowfall and icy/slippery grounds, } \\
\text { the loading area was not sanded; neither } \\
\text { before, under the new fallen snow }\end{array}$ & \multirow{4}{*}{ Unsafe surface } & \\
\hline $\begin{array}{l}\text { Snow and ice, the loading area was sanded, } \\
\text { and it was difficult to pull the heavy pallets } \\
\text { on that surface. }\end{array}$ & & \\
\hline $\begin{array}{l}\text { Snowy rain, when the interviewee rushed } \\
\text { and jumped up on the tailgate lift, that had } \\
\text { become slippery. }\end{array}$ & & \\
\hline etc. & & \\
\hline
\end{tabular}


Table 2. Combinations of the factors identified as contributing to occupational accidents by truck drivers.

\begin{tabular}{|c|c|}
\hline $\begin{array}{l}\text { Number of } \\
\text { contributing } \\
\text { factors }\end{array}$ & The combinations \\
\hline \multirow{2}{*}{4} & $\begin{array}{l}\text { Crowding/disorder, Unsafe handling of goods, Manual lifting, Imbalance between } \\
\text { demands and resources }\end{array}$ \\
\hline & $\begin{array}{l}\text { Unsuitable packaging, Lack of proper equipment, Unloading heavy loads alone, } \\
\text { Imbalance between demands and resources }\end{array}$ \\
\hline \multirow{6}{*}{3} & Crowding/disorder, Manual lifting, Imbalance between demands and resources \\
\hline & $\begin{array}{l}\text { Unsafe surface, Unloading heavy loads alone, Imbalance between demands and } \\
\text { resources }\end{array}$ \\
\hline & Excess stowage, Unsafe construction of equipment, Unsafe handling of goods \\
\hline & Lack of proper equipment, Unloading heavy loads alone, Manual lifting* \\
\hline & Lack of proper equipment, Voluntary participation in un-/loading, Manual lifting \\
\hline & Excess stowage, Unsafe handling of goods, Voluntary participation in un-/loading \\
\hline \multirow{17}{*}{2} & Defective equipment, Unsafe construction of equipment \\
\hline & Lack of proper equipment, Unsafe construction of equipment \\
\hline & Unsafe handling of goods, Voluntary participation in un-/loading \\
\hline & Lack of proper equipment, Unsafe surface* \\
\hline & Defective equipment, Imbalance between demands and resources* \\
\hline & Excess stowage, Imbalance between demands and resources \\
\hline & Crowding/disorder, Imbalance between demands and resources \\
\hline & Unsafe surface, Imbalance between demands and resources* \\
\hline & Manual lifting, Imbalance between demands and resources \\
\hline & Unsafe placement of goods, Imbalance between demands and resources \\
\hline & Unsafe handling of goods, Imbalance between demands and resources \\
\hline & Lack of proper equipment, Imbalance between demands and resources \\
\hline & Unsafe construction of equipment, Inattention/distraction* \\
\hline & Unsafe surface, Inattention/distraction* \\
\hline & Unsuitable packaging, Unloading heavy loads alone \\
\hline & Unsafe construction of equipment, Unsafe surface \\
\hline & Unsafe construction of equipment, Unsafe placement of goods \\
\hline
\end{tabular}


Table 3. Interpretative reflection on stakeholders other than the drivers who directly help prevent accidents.

\begin{tabular}{|c|c|c|c|c|c|c|c|c|c|c|}
\hline & \multicolumn{3}{|c|}{$\begin{array}{l}\text { Goods and } \\
\text { equipment }\end{array}$} & \multicolumn{2}{|c|}{$\begin{array}{l}\text { Loading and } \\
\text { unloading } \\
\text { area }\end{array}$} & \multicolumn{2}{|c|}{$\begin{array}{l}\text { Loading and } \\
\text { unloading } \\
\text { tasks }\end{array}$} & \multirow{2}{*}{ 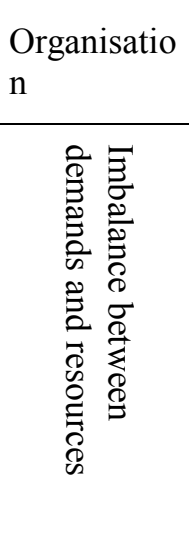 } & \multirow[b]{2}{*}{ 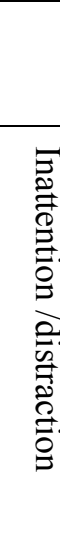 } \\
\hline & & 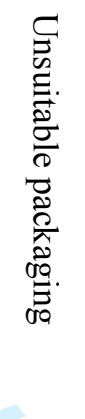 & 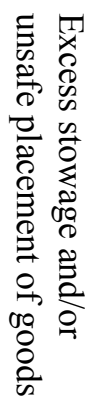 & 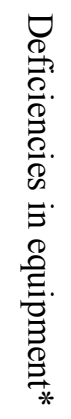 & 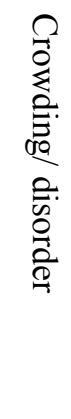 & 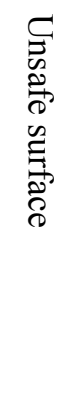 & 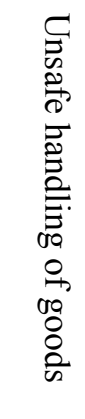 & 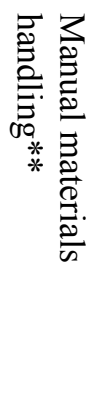 & & \\
\hline \multirow{4}{*}{$\begin{array}{l}\text { Transportation } \\
\text { company }\end{array}$} & Foreman & 10 & & $\mathrm{X}$ & & & & $\mathrm{X}$ & $\mathrm{X}$ & $\mathrm{X}$ \\
\hline & $\begin{array}{l}\text { Top } \\
\text { management }\end{array}$ & $\mathrm{X}$ & $\mathrm{X}$ & $\bar{X}$ & $\mathrm{X}$ & $\mathrm{X}$ & $\mathrm{X}$ & $\mathrm{X}$ & $\mathrm{X}$ & $\mathrm{X}$ \\
\hline & $\begin{array}{l}\text { Terminal } \\
\text { employee }\end{array}$ & $\theta$ & $\mathrm{X}$ & 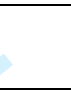 & & & $\mathrm{X}$ & & & \\
\hline & $\begin{array}{l}\text { Route } \\
\text { planner }\end{array}$ & $X$ & $\mathrm{X}$ & & & & $\mathrm{X}$ & & $\bar{X}$ & \\
\hline \multirow{4}{*}{ Client } & $\begin{array}{l}\text { Possible } \\
\text { third parties } \\
\text { that own the } \\
\text { client's } \\
\text { premises }\end{array}$ & & & X & X & X & & & & \\
\hline & The client & & & $X$ & $X$ & $\mathrm{X}$ & & & & \\
\hline & $\begin{array}{l}\text { The client's } \\
\text { personnel }\end{array}$ & & & & $\mathrm{X}$ & $\bar{X}$ & & & & \\
\hline & $\begin{array}{l}\text { Support } \\
\text { service: } \\
\text { Janitorial / } \\
\text { maintenance } \\
\text { / cleaning }\end{array}$ & & & & $\mathrm{X}$ & $\mathrm{X}$ & & & & \\
\hline \multirow{2}{*}{$\begin{array}{l}\text { Technology } \\
\text { designers and } \\
\text { manufacturers }\end{array}$} & $\begin{array}{l}\text { Tools and } \\
\text { aids }\end{array}$ & X & $X$ & & & & & X & & \\
\hline & $\begin{array}{l}\text { Trucks, truck } \\
\text { bodies and } \\
\text { trailers }\end{array}$ & & & & & & X & & & \\
\hline
\end{tabular}

* Combines the categories 'lack of proper equipment', 'unsafe construction of equipment' and 'defective equipment'.

** Combines the categories 'unloading heavy loads alone', 'manual lifting' and 'voluntary participation in un-/loading'. 